\title{
Patient's Experiences of Violence as Perpetrator: A Qualitative Study from Patients with Schizophrenia in Indonesia
}

\author{
Iyus Yosep ${ }^{1 *}$ (D) , Helmy Hazmi ${ }^{2}$, Zabidah Putit $^{3}$ \\ ${ }^{1}$ Department of Mental Health, Faculty of Nursing, Padjadjaran University, Sumedang, Indonesia; ${ }^{2}$ Department of Public Health, \\ Faculty of Medicine, University of Malaysia Sarawak, Sarawak, Malaysia; ${ }^{3}$ Faculty of Pharmacy and Nursing, Medicine and \\ Health Sciences, University of Nizwa, Nizwa, Oman
}

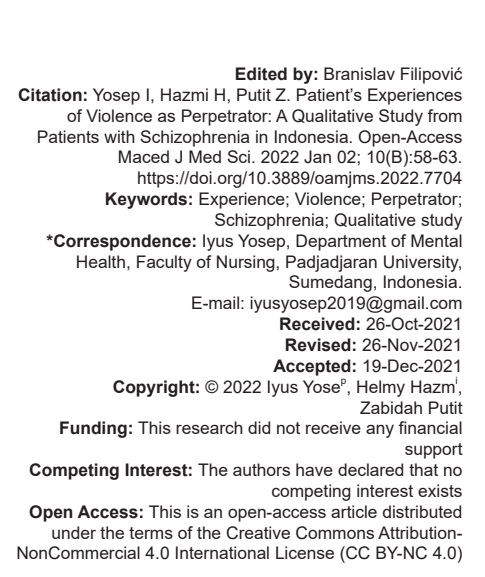

Abstract

BACKGROUND: Individuals with schizophrenia are at an increased risk for violence - limited study on exploring the experience of violence in patients with schizophrenia as a perpetrator.

AIM: This research aimed to investigate the perception of violence as a perpetrator in Indonesia in patients with schizophrenia.

METHODS: This study used phenomenology using a purposive sampling technique. A total of 40 patients were from the psychiatric ward of significant mental hospitals in West Java, Indonesia. The inclusion criteria for patients were the following: Age over 18 years old confirmed diagnosis with schizophrenia. Focus group discussion of patients comprised four groups. Each group consisted of tens of patients.

RESULTS: The patient's experiences as a perpetrator were categorized into six subthemes: Committing physical violence to family, quarreling with family, verbal abuse to family, a perpetrator of verbal violence to neighbors, expression of anger to object, and physical violence to nurse.

CONCLUSION: The patient's experiences of violence were not linear, but rather it was a complex experience of being a perpetrator, yet at the same time as of perpetrator violence. A staff training program to reduce patient violence is needed.

\section{Introduction}

Workplace violence against nurses in the mental health unit and at the hospital in the world is increasing. Patients and their families were the prominent people who abused them with words and bodies. According to Spector et al. [1], 36.4\% of nurses reported bodily injury, $66.9 \%$ reported non-physical violence, $39.7 \%$ reported harassment, and $25 \%$ reported sexual harassment. There is a wide variation in the incidence of workplace violence in different nations; for example, a study conducted in eight European countries found that the prevalence was $40.5 \%$ [2]. While the prevalence in Asian nations such as Egypt was 27.7\% [3] and 38.9\% in Thailand [3], the prevalence in the United States was $20.7 \%$ [2]. More than half of Taiwanese nurses reported being physically or verbally harassed at work [4]. There is a need for additional assessment of nurse abuse in the workplace, particularly in mental health settings, taking these critical factors into account.

Several variables have been highlighted in the literature as contributing to the rise in violence against nurses. The underlying issue is patient and family dissatisfaction with hospital services. High rates of nurse violence result from patient dissatisfaction with nursing care, particularly about interpersonal connections and communication [5], [6]. Other research has revealed that the source of discontent with nurses is primarily related to communication and interpersonal connections [7], [8], [9] suggested that the dissatisfaction of patients and their families concerning the communication element drives them to commit violence against nurses.

Violence done by patients with schizophrenia is frequently recorded in the media, often sensationalized. Violence done by mentally ill patients, on the other hand, is sometimes justified. It is reinforced by research findings that show that psychopathy and clinical variables are substantially connected with the frequency of violent behavior [10]. According to another study, most violence is perpetrated by schizophrenia patients during auditory hallucinations [11], [12]. Calls for more intensive treatment of mental illness to mitigate violent crime are also accompanied by these studies [13]. Of course, the premise behind this view is that psychotic symptoms or psychotic disorders enhance the likelihood of aggression. The psychosis is correlated with a 49-68\% increase in the risk of aggression [14] in a meta-analysis 
of 204 studies based on 166 independent data sets. In addition, most providers of mental health services do not measure or control the risk of violence or offer care for the prevention of violence [15], leading to suboptimal treatment and the continuation of an unnecessarily high risk of violence. Many patients are put in forensic medical settings, jails, or prisons to compound the issue, where there are significant obstacles to having proper mental health treatment [16]. Most (72\%) people with schizophrenia who commit a criminal crime do so before first contact with health services. This fact is expressed in the findings of a recent meta-analysis showing that at least one attack has previously been committed by $35 \%$ of people who approached services for the first episode of psychosis. However, many previous studies were focused on nurses' experience of violence [17], [18], [19], making the experience of violence as a perpetrator unexplored. This research aimed to investigate the perception of violence as a perpetrator in Indonesia in patients with schizophrenia.

\section{Methods}

\section{Study design and sample}

This study was conducted using phenomenology at the psychiatric ward of two mental hospitals in West Java, Indonesia. The inclusion criteria for patients were the following: Age over 18 years old confirmed the diagnosis with schizophrenia and had no acute psychosis symptoms. Patients who had difficulties communicating and uncontrolled treatment were excluded. A total of 40 patients were recruited using a convenience sampling technique.

\section{Data collection}

Three focus group discussions (FGDs) were conducted with patients to make a qualitative assessment of exposure to violence. FGD of patients comprised four groups. Each group consisted of tens of patients. The total number of patients who followed FGD was 40 patients. The patients had been selected by an ethical board team at a mental hospital in West Java, made up of doctors, nurses, psychologists, and social workers. Before attending the FGD, the participants had been selected according to their abilities in social interaction and verbal communication by the Nursing Ethical Board team. Audio recording and notes were taken for the sessions, and all necessary precautions were announced to carry out the session successfully.

\section{Ethics considerations}

The Institutional Oversight Board has been given ethical approval. Studying this sensitive topic, particularly those who might be vulnerable, raised specific ethical issues related to the method of study and the methodology used. In various clinical procedures in psychology and academic areas, like nurses, researchers have professional experience - a thorough review by both the core medical staff and nurses of possible participants. At the time of the initial screening, specifics of the study were given. The voluntary goals of the study, independent consent, parental consent, non-binding consent, the right to withdraw, and the privacy of the findings were conveyed to the participants. Silent consent is not acceptable. Before the interview, participants offered informed permission. The informed consent provided participants with the opportunity to answer their inquiries, good questioning, and active listening. In the context of this violence research question, however, concerns such as parents transportation problems, coordination, and in-depth discussions with hospitals can be discussed.

\section{Data analysis}

Data analysis was conducted using Colaizzi's technique [20]. There are seven steps to completing the analysis. In the first step, the interviewee's statement was read and reread to get a general sense of what they have been through. The second step is to take the most critical statements from the text to get information directly related to phenomenon studies. The third steps write definitions in scientific language to show how different phenomenon contexts are related to each other. The fourth step is to group them into theme clusters and cross-reference them to the original text. In the fifth step, the discovery was then combined into a succinct explanation of the desired phenomenon and returned to the participant for confirmation (Step 6). The final step is to implement any changes recommended by the informants.

\section{Rigor}

The research team conducted the interviews. Two researchers' coders conducted an independent study of the interviews. Strategies were adopted to promote the researchers' credibility, meaning, skills, and knowledge, a thick summary of the participants' fascinating encounters, frequent debriefing times, and discussions that provided the researchers with an opportunity to test and scrutinize the interpretation of the ideas and expectations between them. To facilitate transferability, a thorough explanation of the context, identification and explanations of respondents and data collection procedures, and a rich representation of the findings, along with appropriate quotations of the participant's own words, was provided. To encourage reliability, the research design was specified. The researchers have discussed results to guarantee reliability. A description of the findings has been submitted to the respondents for confirmation; none of this has been disputed. 


\section{Findings}

\section{Committing physical violence to family}

Throughout their lifespan, schizophrenic patients spent most of their time at home with their families rather than at the hospital. Therefore, the tendency to commit physical violence to their family was high. Physical attacks become a typical scenario where the patient "beat, struck, attack, amok, hit, berserk, burn, amok or burn anything." This physical violence often coincides with the rise of verbal violence to family members such as to their son, husband, or mother. The following excerpts are explained

- $\quad$ (A8) - "I screwed up at home, and I beat my son."

- $\quad$ (A9) - "If I do not agree, yes ... I beat my mother."

- $\quad$ (C1) - "My behavior was like a criminal, often striking and attacking people, and often got drunk."

- $\quad$ (D2) - "Money to buy cigarettes had been thrown to me by my parents, and then I beat them right away."

- (D9) - "I beat someone, got awry, ran amok, burned pillows, and removed the furniture anyhow."

\section{Quarreled with family}

A quarrel was when the patients had an angry argument or disagreement when interacting with their family. They usually took exception to anything or disagreed with something. Schizophrenic patients often get angry, crushing, reprimanding, fighting, and become grumpy. The following sentences indicate that schizophrenic patients have had some experience in heated arguments and quarreled with their family members.

This can be seen in the following data:

- (A6) - "If I become angry, I crush pillows."

- $\quad$ (A9) - "I am angry with my mother since she only took care of her younger half-brother."

- (C1) - "My boyfriend reprimanded me. I reprimanded behind my parents."

(D1) - "I fought against my family."

(D2) - "I often got grumpy; goods were so messy at my house."

\section{Verbal abuse to family}

In Indonesian culture and language, humiliating someone or abusing own family members can be demonstrated in harsh words. The characteristics of a very harsh language are marked by the appearance of "animal symbols" in communication that is considered more despicable. This can be seen in examples such as "dog, pig, pot-bellied, etc." In addition, words such as "angry" or "grumpy" may indicate that the patient has also flared with verbal abuse. For more details, see the following:

- $\quad$ (C4) - "I said to my family: Which points should come first, the truth or Islamic law? You are like dog, pig, pot-bellied."

- $\quad$ (A9) - "I was angry with my mother because she only gave attention and took care of her younger half-brother."

(B1) - "I was grumpy at my parents. It is normal."

The perpetrator of verbal violence to neighbors

Schizophrenic patients who have completed treatment at a mental hospital will return to their families. While at home with their family, they interact with their neighbors. However, during a hallucination, the patients could not control their emotions. In addition, when the patient is engaged in a "conflict with the neighbor," the coping mechanism employed is not always constructive. Patients are often in conflict with their neighbors. The essential keywords that appear over and over in the patients' transcripts were their "Neighbors" as indicated by the following sentences:

- (A8) - "I was hyperactive, cursing and damaging neighbor's roof-tile, and could not sleep. Finally, my temper exploded, breaking my neighbor's roof-tile."

- (B1) - "I was grumpy at my parents; I also often did it to my neighbors."

- (C4) - "Because my desire to argue loudly while pointing at neighbors."

\section{Expression of anger to object}

In addition to expressing anger to family, neighbors, or nurses verbally, patients also express their anger by destroying objects. The items around their house such as' mattresses, pillows, and furniture were used as the object to express their anger. This patients' emotional expression is a form of communication in which they tell their neighbor that they "disagree." According to the patient, the problem could not be solved anymore with regular communication. The data that appeared are as follows:

- $\quad$ (D1) - " There were whisperings of demons and voices that ordered me to burn the mattress." (D9) - "Beating, awry, amok, burning cushions, removing furniture."

(C4) - "Initially, I was going berserk in my house."

- (DI) - "I want to hit; I went berserk at my home."

\section{Physical violence to nurse}

Of the 40 patients who attended the FGD, only two could verbalize that he had committed physical abuse to the nurses. This physical violence can be seen from the keyword data such as "bite" or "hit" the nurse. For more details, see the data below: 
(D3) - "I would like to talk at random; immediately, I hit a nurse and rage violently." (C8) - "I bit my nurse's leg."

\section{Discussion}

This study found that patients admitted to threatening their neighbors. This is supported by Gerlinger et al. [21] report concluding that most mental patients have the stigma, particularly shyness or isolation from their neighbors. However, in schizophrenia patients, it appears to be influenced by the hearing hallucination that instructs them to do destructive something. In addition, the typical symptoms of severe schizophrenia are the inability to distinguish between fantasy and reality [22]. This study showed that patients have violence against their neighbors in this study. This finding is consistent with earlier studies [23], [24], [25].

Some patients never resorted to physical violence in their family, staff, or neighbor. However, in this study, especially from the "nurses' perspective," it was found that the patient has done violence physically, psychologically, verbally, and sexually abused on nurses, although it has occurred on various scales. This finding is supported by earlier studies concluding that "Nurse exposure to physical and non-physical violence, bullying, and sexual harassment" [1], [5]. Physical violence occurs as a result of hallucination, expression of anger, or clients' communication to express their feelings. This finding confirmed the results of the FGD followed by staff. The results of nurse FGD suggest high physical violence by patients in the mental hospital. Several studies found that most incidents were reported by nurses, security staff, and nurse assistants [26]. This supports the findings of FGD in the group followed by the patients. In addition, research has shown that positive actions of employees can dramatically decrease violent behavior. For instance, violence and aggression toward employees decreased when patients viewed staff responses as collaborative, validating, and valuable [27]. In addition, seclusion, restraint, and employee disability decreased as employee maturity in demonstrating therapeutic interpersonal skills increased [28].

Violence is not inevitable among people with psychotic disorders. Risk factors may be evaluated, and appropriate treatment modalities, including inpatient and outpatient facilities, occur across a continuum of care. Programs providing evidence-based services that target abuse, however, are uncommon. In addition, due to medical concerns about its chances of potentially lethal side effects, clozapine, the only antipsychotic drug that has been proven to reduce abuse in psychotic patients substantially is under-prescribed in the population. Programs such as FACT or the more violent AOT can be helpful to avoid the incidence of illegal activity and imprisonment in patients who are not adherent to therapy. In addition to the direct benefit to the patient, the stigma associated with severe mental illness can also be minimized by reducing the causes of aggression among psychotic individuals. As noted by [29], attempts to encourage a more optimistic perception of people with psychosis are less likely to be successful in stigma reduction than actively reducing violent actions. However, this involves a systematic approach [30] that includes identifying the multiple contributions of disease-related causes (e.g., unique psychotic symptoms and traits of antisocial personality), drug abuse, socioeconomic factors such as poverty, and mental health system issues, including lack of risk evaluation of violence and insufficient care opportunities.

Develop an electronic system is needed to help nurse. In addition, it is critical to give nurses legal immunity and establish an ethics committee that can protect the interests of nurses and patients. It is critical to protect nurses from litigation and form an ethics committee that can protect "nurses' or patients' rights." In addition, it is planned to establish an insurance scheme for nurses working in mental hospitals, emphasizing physical and psychological stress. Future research examining additional factors linked with violence among patients with mental health disorders in Indonesia is also justified to gain a better grasp of the country's significant concerns with violence.

\section{Limitations}

To begin, some of our findings may be difficult to extrapolate to other countries. However, we observed two characteristics of patients acting as perpetrators relevant to other nations. In addition, there are few qualitative studies on violence perpetrated by patients. Thus, our findings may help identify future study topics. Second, interviewees were selected from hospital-based activity groups; consequently, patients who do not participate in these groups may have more severe instances.

\section{Conclusion}

The patient's experiences as a perpetrator were categorized into six subthemes: Committing physical violence to family, quarreling with family, verbal abuse to family, the perpetrator of verbal violence to neighbors, expression of anger to object, and physical violence to nurse. Having medicine for an illness can sometimes stop people from angry, but this is not always the case. Patients can get help from nurses to get over their aggression quickly, taking into account other treatments such as therapy or independent living. Psychoeducation would be beneficial to reduce the 
amount of time spent evaluating and selecting coping mechanisms. Future studies examine further how the process of coping with violence could be vital for people with schizophrenia.

\section{References}

1. Spector PE, Zhou ZE, Che XX. Nurse exposure to physical and nonphysical violence, bullying, and sexual harassment: A quantitative review. Int J Nurs Stud. 2014;51(1):72-84. https:// doi.org/10.1016/j.ijnurstu.2013.01.010

PMid:23433725

2. Kamchuchat C, Chongsuvivatwong V, Oncheunjit S, Yip TW, Sangthong R. Workplace violence directed at nursing staff at a general hospital in southern Thailand. J Occup Health. 2008;50(2):201-7. https://doi.org/10.1539/joh.07001 PMid: 18403873

3. Abbas RA, Selim SF. Workplace violence: A survey of diagnostic radiographers in Ismailia governorate hospitals. Egypt J Am Sci. 2011;7:1049-58.

4. Lee S, Pai HC, Yen WJ. Nurse violence in the workplace: A study of experiences and related factors in Taiwan. $\mathrm{Hu} \mathrm{Li} \mathrm{Za}$ Zhi. 2010;57(2):61-9. PMid:20401868

5. Speroni KG, Fitch T, Dawson E, Dugan L, Atherton M. Incidence and cost of nurse workplace violence perpetrated by hospital patients or patient visitors. J Emerg Nurs. 2014;40(3):218-28; quiz 295. https://doi.org/10.1016/j.jen.2013.05.014 PMid:24054728

6. Purpora C, Blegen MA. Job satisfaction and horizontal violence in hospital staff registered nurses: The mediating role of peer relationships. J Clin Nurs. 2015;24(15-16):2286-94. https://doi. org/10.1111/jocn.12818

PMid:25939756

7. Fakhr-Movahedi A, Salsali M, Negharandeh R, Rahnavard Z. A qualitative content analysis of nurse-patient communication in Iranian nursing. Int Nurs Rev. 2011;58(2):171-80. https://doi. org/10.1111/j.1466-7657.2010.00861.x

PMid:21554289

8. Lyndon A, Zlatnik MG, Wachter RM. Effective physiciannurse communication: A patient safety essential for labor and delivery. Am J Obstet Gynecol. 2011;205(2):91-6. https://doi. org/10.1016/j.ajog.2011.04.021

PMid:21640970

9. Manojlovich M. Nurse/physician communication through a sensemaking lens: Shifting the paradigm to improve patient safety. Med Care. 2010;48(11):941-6. https://doi.org/10.1097/ MLR.0b013e3181eb31bd PMid:20829721

10. Doyle M, Carter S, Shaw J, Dolan M. Predicting community violence from patients discharged from acute mental health units in England. Soc Psychiatry Psychiatr Epidemiol. 2012;47(4):627-37. https://doi.org/10.1007/s00127-011-0366-8 PMid:21390510

11. Bucci S, Birchwood M, Twist L, Tarrier N, Emsley R, Haddock G. Predicting compliance with command hallucinations: Anger, impulsivity and appraisals of voices' power and intent. Schizophr Res. 2013;147():163-8. https://doi.org/10.1016/j. schres.2013.02.037

PMid:23537476
12. Scott CL, Resnick PJ. Evaluating psychotic patients' risk of violence: A practical guide: Investigate persecutory delusions and command hallucinations. Curr Psychiatr. 2013;12:28-33.

13. Richard-Devantoy S, Olie JP, Gourevitch R. Risk of homicide and major mental disorders: A critical review. Encephale. 2009;35(6):521-30. https://doi.org/10.1016/j.encep.2008.10.009 PMid:20004282

14. Douglas KS, Hart SD, Webster CD, Belfrage H, Guy LS, Wilson CM. Historical-clinical-risk management-20, version 3 (HCR-20V3): Development and overview. Int J Forensic Ment Health. 2014;13(2):93-108. https://doi.org/10.1080/14999013 .2014 .906519

15. Hodgins $S$, Lincoln T, Mak T. Experiences of victimisation and depression are associated with community functioning among men with schizophrenia. Soc Psychiatry Psychiatr Epidemiol. 2009;44(6):448-57. https://doi.org/10.1007/s00127-008-0460-8 PMid:19030767

16. Gonzalez JM, Connell NM. Mental health of prisoners: Identifying barriers to mental health treatment and medication continuity. Am J Public Health. 2014;104(12):2328-33. https:// doi.org/10.2105/AJPH.2014.302043

PMid:25322306

17. Yosep I, Mediani HS, Sriati A. Experiences of violence among individuals with schizophrenia in Indonesia: A phenomenologica study. J Psychosoc Nurs Ment Health Serv. 2021;59(11):41-6. https://doi.org/10.3928/02793695-20210528-01 PMid:34251933

18. Baby M, Glue P, Carlyle D. 'Violence is not part of our job': A thematic analysis of psychiatric mental health nurses' experiences of patient assaults from a New Zealand perspective. Issues Ment Health Nurs. 2014;35(9):647-55. https://doi.org/10. 3109/01612840.2014.892552

PMid:25162186

19. Stevenson KN, Jack SM, O'Mara L, LeGris J. Registered nurses' experiences of patient violence on acute care psychiatric inpatient units: An interpretive descriptive study. BMC Nurs. 2015;14:35. https://doi.org/10.1186/s12912-015-0079-5 PMid:25999795

20. Creswell JW, Poth CN. Qualitative Inquiry and Research Design: Choosing among Five Approaches. New York, United States: Sage Publications; 2016.

21. Gerlinger G, Hauser M, De Hert M, Lacluyse K, Wampers M, Correll CU. Personal stigma in schizophrenia spectrum disorders: A systematic review of prevalence rates, correlates, impact and interventions. World Psychiatry. 2013;12(2):155-64. https://doi.org/10.1002/wps.20040 PMid:23737425

22. Imai A, Hayashi N, Shina A, Sakikawa N, Igarashi Y. Factors associated with violence among Japanese patients with schizophrenia prior to psychiatric emergency hospitalization: A case-controlled study. Schizophr Res. 2014;160(1-3):27-32. https://doi.org/10.1016/j.schres.2014.10.016 PMid:25458570

23. Bhavsar V, Dean K, Hatch SL, MacCabe JH, Hotopf M. Psychiatric symptoms and risk of victimisation: A population-based study from Southeast London. Epidemiol Psychiatr Sci. 2019;28(2):168-78. https://doi.org/10.1017/S2045796018000537 PMid:30196801

24. Millier A, Schmidt U, Angermeyer MC, Chauhan D, Murthy V, Toumi M, et al. Humanistic burden in schizophrenia: A literature review. J Psychiatr Res. 2014;54:85-93. https://doi. org/10.1016/j.jpsychires.2014.03.021 PMid:24795289

25. Jack A, Egan V. Paranoid thinking, cognitive bias and dangerous neighbourhoods: Implications for perception of 
threat and expectations of victimisation. Int $\mathrm{J}$ Soc Psychiatry. 2016;62(2):123-32. https://doi.org/10.1177/0020764015599998 PMid:26290397

26. Arnetz JE, Fitzpatrick L, Cotten SR, Jodoin C, Chang CD. Workplace bullying among nurses: Developing a model for intervention. Violence Vict. 2019;34(2):346-62. https://doi. org/10.1891/0886-6708.VV-D-17-00211

PMid:31019016

27. Marth D. A Longitudinal Study of Differences in Staff Assaults by Responses to Residents in a Forensic Hospital; 2009.
28. Donat DC. Impact of improved staffing on seclusion/restraint reliance in a public psychiatric hospital. Psychiatr Rehabil J. 2002;25:413.

29. Torrey EF. Stigma and violence: Isn't it time to connect the dots? Schizophr Bull. 2011;37:892-6. https://doi.org/10.1093/schbul/ sbr057

PMid:21653276

30. Schanda P. Fast-pulsing longitudinal relaxation optimized techniques: Enriching the toolbox of fast biomolecular NMR spectroscopy. Prog Nucl Magn Reson Spectrosc. 2009;55:238-65. 